\title{
Radiance Temperature of Niobium at its Melting Point*
}

\author{
Ared Cezairliyan \\ Institute for Materials Research, National Bureau of Standards, Washington, D.C. 20234
}

(January 29, 1973)

\begin{abstract}
A subsecond duration pulse heating method is used to investigate variations in the radiance temperature (at $650 \mathrm{~nm}$ ) of niobium near and at its melting point. Measurements were made on several specimens with different surface conditions. The results do not indicate any dependence of radiance temperature (at the melting point) on initial surface conditions. The average radiance temperature (at $650 \mathrm{~nm}$ ) at the melting point for twelve different niobium specimens is $2425 \mathrm{~K}$ on the International Practical Temperature Scale of 1968, with an average absolute deviation of $0.6 \mathrm{~K}$ and a maximum deviation of $1.2 \mathrm{~K}$.
\end{abstract}

Key words: High-speed measurements; high temperature; melting; niobium; radiance temperature; surface roughness.

\section{Introduction}

In an earlier publication $[1],{ }^{1}$ the application of a millisecond resolution pulse heating technique to the measurement of the melting point of niobium was described. In the same publication, preliminary reresults for the normal spectral emittance (at $650 \mathrm{~nm}$ ) of two niobium specimens at the melting point were also presented. Normal spectral emittance was obtained from the measurements of the melting point and the radiance temperature at the melting point.

In general, specimen radiance temperature at a given true temperature is not a reproducible quantity. Radiance temperature depends on specimen surface conditions, thus it varies from specimen to specimen (of the same substance) and it may even be different for the same specimen at different times and under different environments.

However, the preliminary results of radiance temperature measurements for the two different specimens reported in the earlier study [1] were within $1.5 \mathrm{~K}$ of each other at the melting point of niobium $(2750 \mathrm{~K})$. This has suggested the possibility that radiance temperature (at the melting point) may be independent of surface conditions of the solid specimen, thus it may be a reproducible quantity for pure specimens of similar thermal history.

The objective of this paper is to further investigate the melting behavior of niobium and to report the results of recent accurate measurements, utilizing a pulse heating technique, of the radiance temperature of niobium near and at its melting point.

\footnotetext{
*This work was supported in part by the U.S. Air Force Office of Scientific Research.

${ }^{1}$ Figures in brackets indicate the literature references at the end of this paper.
}

\section{General Considerations}

Melting of a pure metal is manifested by a plateau in the temperature versus time curve as shown in figure 1 (Case 1). Since in the figure the heating curve is represented by the specimen radiance temperature, validity of the shape of the curve is based on the assumption that the normal spectral emittance of the metal does not change during the solid-to-liquid transition. For real surfaces this assumption is not satisfied, and it is likely that one obtains a heating curve similar to the one shown in figure 1 (Case 2). The drop at the beginning of the plateau corresponds to the change in normal spectral emittance of the metal surface as it melts. An initial high radiance temperature (peak of spike) indicates that normal spectral emittance of the solid surface is higher than that of the liquid surface. This is likely to be the case, in general, since solid surfaces, regardless of the degree of polish, depart from the conditions of ideal smoothness.

\section{Method}

The method is based on resistive self-heating of the specimen from room temperature to its melting point in less than one second and measuring, with millisecond resolution, the pertinent experimental quantities. The specimen's radiance temperature was measured with a high-speed photoelectric pyrometer [2], which permits 1200 evaluations of specimen temperature per second. A schematic diagram showing the arrangement of the specimen and the pyrometer is presented in figure 2. The radiance measurements were performed at $650 \mathrm{~nm}$ which corresponds to the effective wavelength of the pyrometer's interference 


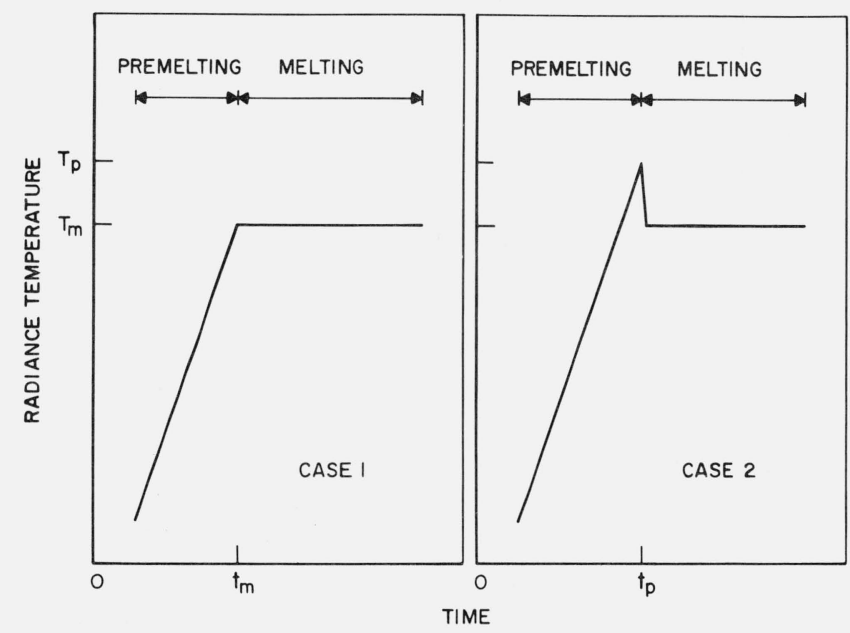

FIGURE 1. Radiance temperature of pure metals near and at their melting points.

Case 1 is based on the assumption that normal spectral emittance does not change during the solid-to-liquid transition, and Case 2 is based on the assumption that normal spectral emittance of the solid surface is higher than that of the liquid surface at the melting point.

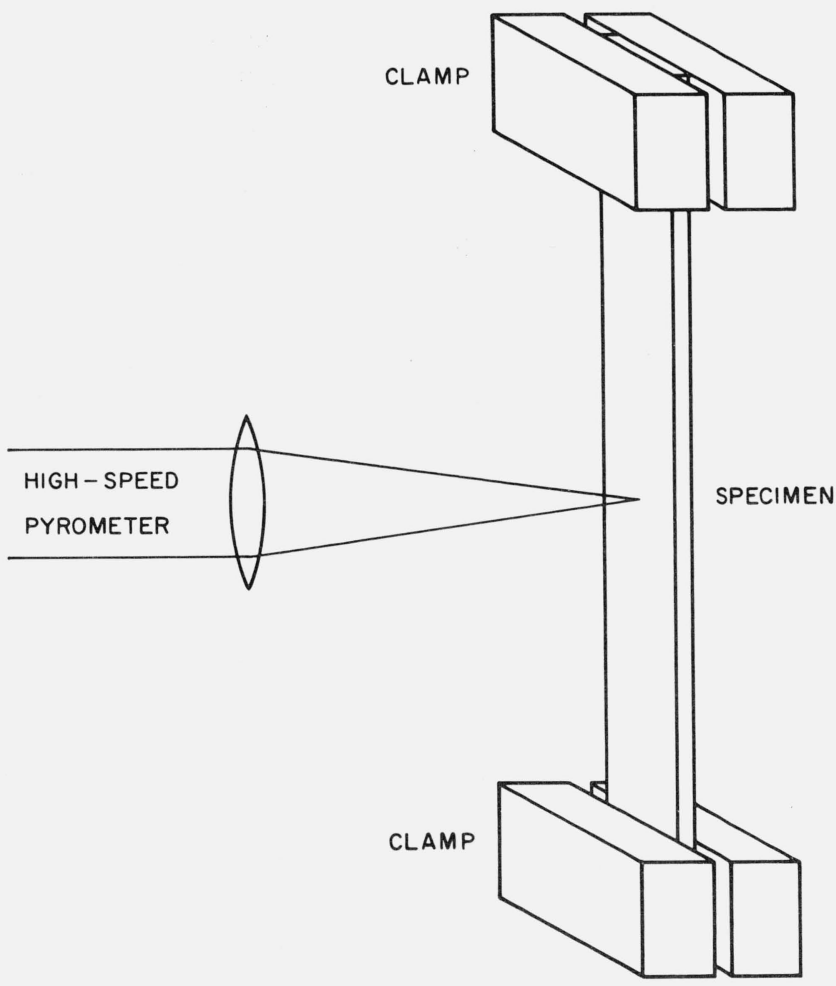

FIGURE 2. Schematic diagram showing the arrangement of the specimen, clamps, and the pyrometer (dimensions are not to scale).

filter. The bandwidth of the filter was $10 \mathrm{~nm}$. The circular area viewed by the pyrometer was $0.2 \mathrm{~mm}$ in diameter. The recordings of temperature were made with a high-speed digital data acquisition system [3], which is capable of recording data at the rate of 2400 points per second with a full-scale signal resolution of approximately one part in 8000 . Details regarding the construction and operational characteristics of the entire measurement system are given in an earlier publication [4].

\section{Measurements}

The niobium specimens were in the form of strips with the following nominal dimensions: length, $75 \mathrm{~mm}$; width, $6.3 \mathrm{~mm}$; and thickness, $0.25 \mathrm{~mm}$. All of the specimens were from the same lot and were $99.9^{+}$ percent pure. Manufacturer's analysis indicated the presence of the following impurities in ppm by weight: Ta, 210; Hf and W, < 100 each; Fe, Mo and $\mathrm{Zr},<50$ each; Al, Ca, Cr, Co, Cu, Mg, Mn, Ni, Pb, Si, Sn, Ti, $\mathrm{V},<20$ each; Cd, <5; O, 42; N, 25; C, 14; H, 5 .

A total of 12 experiments were performed on 12 different specimens. Eight of the experiments were conducted on specimens with surfaces in the "as received" conditions (smooth and shiny). The remaining four experiments were performed on specimens with three different surface roughnesses, which were achieved by using different grades of sand paper. The RMS surface roughness of a typical "as received" specimen was $0.10 \mu \mathrm{m}$, and for the others it ranged from 0.38 to $0.95 \mu \mathrm{m}$, yielding a factor of approximately 10 for the overall variation in surface roughness.

In nine of the experiments the specimens were in a vacuum environment of approximately $10^{-5}$ torr, and in three of the experiments the specimens were in an argon environment at approximately atmospheric pressure.

The specimens were initially annealed by the manufacturer. Ten of the experiments were performed without any additional heat treatment. In two of the cases, the specimens were further annealed in the laboratory before the experiments by subjecting them to 30 heating pulses (up to $2400 \mathrm{~K}$ ).

Different heating rates, ranging from $1000 \mathrm{~K} \mathrm{~s}^{-1}$ to $20,000 \mathrm{~K} \mathrm{~s}^{-1}$, were used in the experiments. This corresponds to specimen heating periods (from room temperature to the melting point) in the range from $40 \mathrm{~ms}$ to $800 \mathrm{~ms}$. The magnitude of current pulses near the melting point was in the range from 200 to $600 \mathrm{~A}$. The high-speed pyrometer was calibrated during the period between experiments 7 and 8 against a tungsten filament standard lamp, which in turn was calibrated against the NBS Temperature Standard.

A summary of the experimental procedure is given in table 1. All measurements reported in this paper are based on the International Practical Temperature Scale of 1968 [5].

\section{Experimental Results}

The radiance temperature of niobium at its melting point for the 12 experiments (corresponding to 12 specimens) and other pertinent results are given in table 1. Oscilloscope trace photographs of specimen radiance as measured with the high-speed pyrometer for two typical experiments representing two specimens having different initial surface conditions ("smooth" and "rough") are shown in figure 3. Com- 
TABLE 1. Summary of experiments for the measurement of radiance temperature of niobium during melting

\begin{tabular}{|c|c|c|c|c|c|c|c|c|c|c|c|}
\hline \multirow{2}{*}{$\begin{array}{l}\text { Specimen } \\
\text { number }{ }^{\text {a }}\end{array}$} & \multirow{2}{*}{$\begin{array}{c}\text { Surface } \\
\text { condition }^{b}\end{array}$} & \multirow[b]{2}{*}{ Environment } & \multicolumn{3}{|c|}{ Premelting Period } & \multicolumn{5}{|c|}{ Melting Period } & \multirow{2}{*}{$\begin{array}{c}\text { Temp. diff } \\
\text { peak and } \\
\text { plateau }^{j} \\
\mathrm{~K}\end{array}$} \\
\hline & & & $\begin{array}{c}\text { Heating } \\
\text { rate } \\
\mathrm{K} \mathrm{s}^{-1}\end{array}$ & $\begin{array}{l}\text { Stand. } \\
\text { dev. }^{c} \\
\text { K }\end{array}$ & $\begin{array}{l}\text { Rad. temp. } \\
\text { at peak } \\
\text { K }\end{array}$ & $\begin{array}{l}\text { Number } \\
\text { of temp. }\end{array}$ & $\begin{array}{c}\text { Slope at } \\
\text { plateau }^{\mathrm{f}} \\
\mathrm{K} \mathrm{s}^{-1}\end{array}$ & $\begin{array}{c}\text { Plateau } \\
\text { temp. diff. }{ }^{\mathrm{s}} \\
\mathrm{K}\end{array}$ & $\begin{array}{c}\text { Rad. } \\
\text { temp. } \\
\text { K }\end{array}$ & $\begin{array}{l}\text { Stand. } \\
\text { dev. }{ }^{i} \\
\text { K }\end{array}$ & \\
\hline $\begin{array}{r}1 \\
2 \\
3 \\
4 \\
5 \\
6 \\
7 \\
8 \\
9 \\
10 \\
11 \\
12\end{array}$ & $\begin{array}{l}\text { rough-L } \\
\text { smooth } \\
\text { smooth } \\
\text { rough-M } \\
\text { rough-H } \\
\text { rough-M } \\
\text { smooth } \\
\text { smooth } \\
\text { smooth } \\
\text { smooth } \\
\text { smooth } \\
\text { smooth }\end{array}$ & $\begin{array}{l}\text { vacuum } \\
\text { vacuum } \\
\text { vacuum } \\
\text { vacuum } \\
\text { vacuum } \\
\text { vacuum } \\
\text { vacuum } \\
\text { vacuum } \\
\text { vacuum } \\
\text { argon } \\
\text { argon } \\
\text { argon }\end{array}$ & $\begin{array}{r}2500 \\
2900 \\
2800 \\
2800 \\
2700 \\
2600 \\
1000 \\
3000 \\
2300 \\
2400 \\
11400 \\
20700\end{array}$ & $\begin{array}{r}0.6 \\
.5 \\
.5 \\
.4 \\
.4 \\
.5 \\
.5 \\
.4 \\
.4 \\
.5 \\
.6 \\
.6\end{array}$ & $\begin{array}{l}2444.0 \\
2429.7 \\
2430.1 \\
2456.5 \\
2460.3 \\
2452.3 \\
2429.9 \\
2428.9 \\
2429.6 \\
2429.7 \\
2423.7 \\
2424.9\end{array}$ & $\begin{array}{r}37 \\
90 \\
92 \\
31 \\
30 \\
91 \\
106 \\
54 \\
95 \\
32 \\
20 \\
12\end{array}$ & $\begin{array}{r}-14.7 \\
2.4 \\
-3.6 \\
-9.3 \\
-11.6 \\
9.9 \\
-0.8 \\
6.3 \\
-7.0 \\
-13.3 \\
-7.6 \\
10.3\end{array}$ & $\begin{array}{r}-0.4 \\
.2 \\
-.3 \\
-.2 \\
-.3 \\
.7 \\
-.1 \\
.3 \\
-.6 \\
-.4 \\
-.1 \\
.1\end{array}$ & $\begin{array}{l}2424.0 \\
2424.9 \\
2425.6 \\
2424.5 \\
2425.2 \\
2424.8 \\
2425.9 \\
2424.2 \\
2425.2 \\
2425.8 \\
2423.7 \\
2424.9\end{array}$ & $\begin{array}{r}0.5 \\
.4 \\
.5 \\
.5 \\
.3 \\
.6 \\
.4 \\
.3 \\
.4 \\
.5 \\
.5 \\
1.4\end{array}$ & $\begin{array}{r}20.0 \\
4.8 \\
4.5 \\
32.0 \\
35.1 \\
27.5 \\
4.0 \\
4.7 \\
4.4 \\
3.9 \\
0 \\
0\end{array}$ \\
\hline
\end{tabular}

a Also represents the experiments in chronological order.

${ }^{b}$ The notations used for surface conditions correspond to the following typical roughnesses in $\mu \mathrm{m}$ : smooth, 0.10 ; rough- $\mathrm{L}, 0.38$; rough- $\mathrm{M}, 0.53$; rough- $\mathrm{H}, 0.95$.

c Represents standard deviation of an individual temperature as computed from the difference between the measured value and that from the smooth temperature versus time function (quadratic) obtained by the least squares method. Data extends approximately $100 \mathrm{~K}$ below the melting point.

Maximum radiance temperature that corresponds to the peak of the spike in temperature observed just before melting of specimen. e Number of temperatures used in averaging the results at the plateau to obtain an average value for the radiance temperature at the melting point of the specimen.

f Derivative of the temperature versus time function obtained by fitting the temperature data at the plateau to a linear function in time using the least squares method.

${ }^{g}$ Maximum radiance temperature difference between the beginning and the end of the plateau based on the linear temperature versus time function.

$\mathrm{h}$ The average (for a specimen) of measured radiance temperatures at the plateau.

${ }^{i}$ Standard deviation of an individual temperature as computed from the difference between the measured value and that from the average plateau radiance temperature.

${ }^{j}$ Difference between peak and average plateau radiance temperatures. 


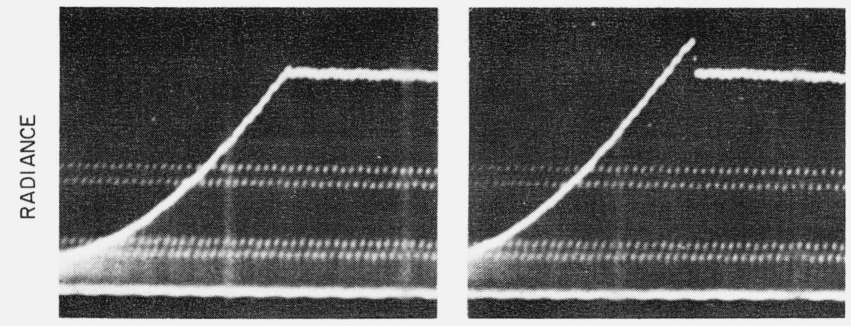

TIME, $\vdash 50 \mathrm{~ms} \dashv$

FIGURE 3. Oscilloscope trace photograph of specimen radiance near and at its melting point as measured with the high-speed pyrometer.

Photograph on the left is for specimen-2 having a "smooth" surface. Photograph on the right is for specimen- 5 having a "rough" surface. Radiance is in arbitrary units.

parison of the traces in figures 1 and 3 verifies the assumptions made regarding the shape of the traces in figure 1. Figure 4 shows the variation of radiance temperature as a function of time near and at the melting point for five typical experiments. These experiments were selected to represent different specimen surface and operational conditions. All the curves, with the exception of "A", show spikes of varying magnitude. The specimen heating rate in experiments corresponding to curves " $\mathrm{B}$ ", " $\mathrm{C}$ ", " $\mathrm{D}$ ", and "E" were four times slower than that of " $A$ ". Thus, the lack of a spike in curve " $A$ " may be attributed to the inability of the system to detect it. It is interesting to observe that, regardless of the initial surface and operational conditions, radiance temperature at the melting plateau is approximately the same for all the specimens.

The radiance temperatures at the peak of the spike as well as at the plateau for the 12 specimens are shown in figure 5. It may be seen that the two fast experiments do not show any peak for reasons discussed above. For the same "smooth" surface conditions, the results of six experiments give approximately the same value (within $1 \mathrm{~K}$ ) for the peak temperature, which is $4.4 \mathrm{~K}$ higher than the plateau temperature. Further changes in the heating rate (slowing down) did not affect the results. The experiments on specimens with initially rough surfaces yielded high peak temperatures; however, the plateau temperatures were in good agreement (within $1 \mathrm{~K}$ ) with those of other specimens. The greatest difference between peak and plateau temperatures, corresponding to the specimen with the roughest surface, is $35 \mathrm{~K}$.

A single value for the radiance temperature at the plateau for each specimen was obtained by averaging the temperatures at the plateau. The number of temperatures used for averaging ranged from 12 to 106 depending on the speed of the experiment and the behavior of the specimen during melting. The standard deviation of an individual temperature from the average was in the range from 0.3 to $0.6 \mathrm{~K}$, with the exception of the very fast experiment which yielded $1.4 \mathrm{~K}$. The details of the results for each experiment are given in table 1. To determine the trend of measured temperatures at the plateau, temperatures for each experiment

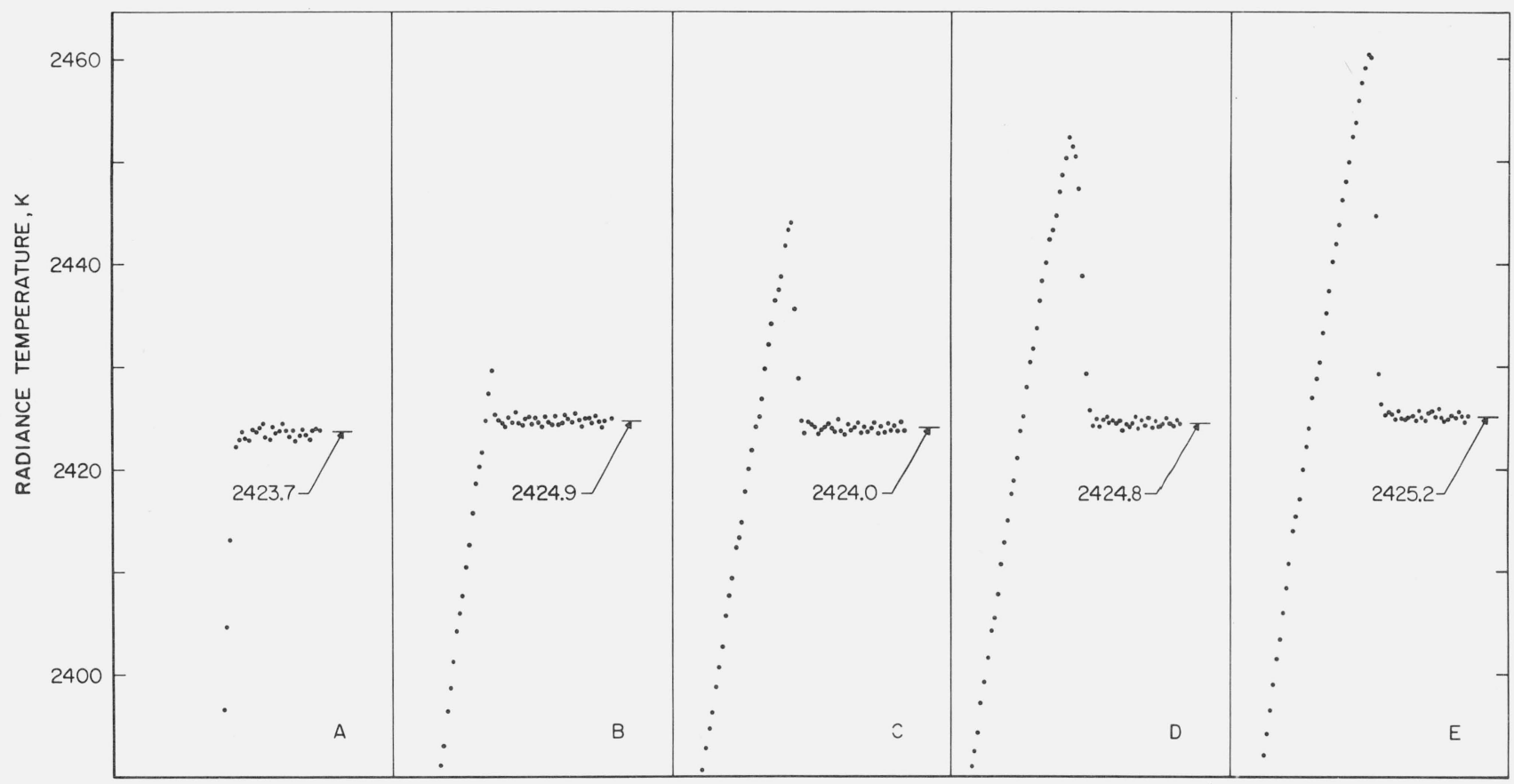

TIME, $10 \mathrm{~ms}$

FIGURE 4. Variation of radiance temperature (at $650 \mathrm{~nm}$ ) of niobium as a function of time near and at its melting point for five typical experiments.

Time interval between consecutive temperature points in $0.833 \mathrm{~ms}$. Correspondence between curve codes and experiment numbers are as follows: A, 11 ; B, 2 ; C, 1 ; D, 6 ; E, 5 . 


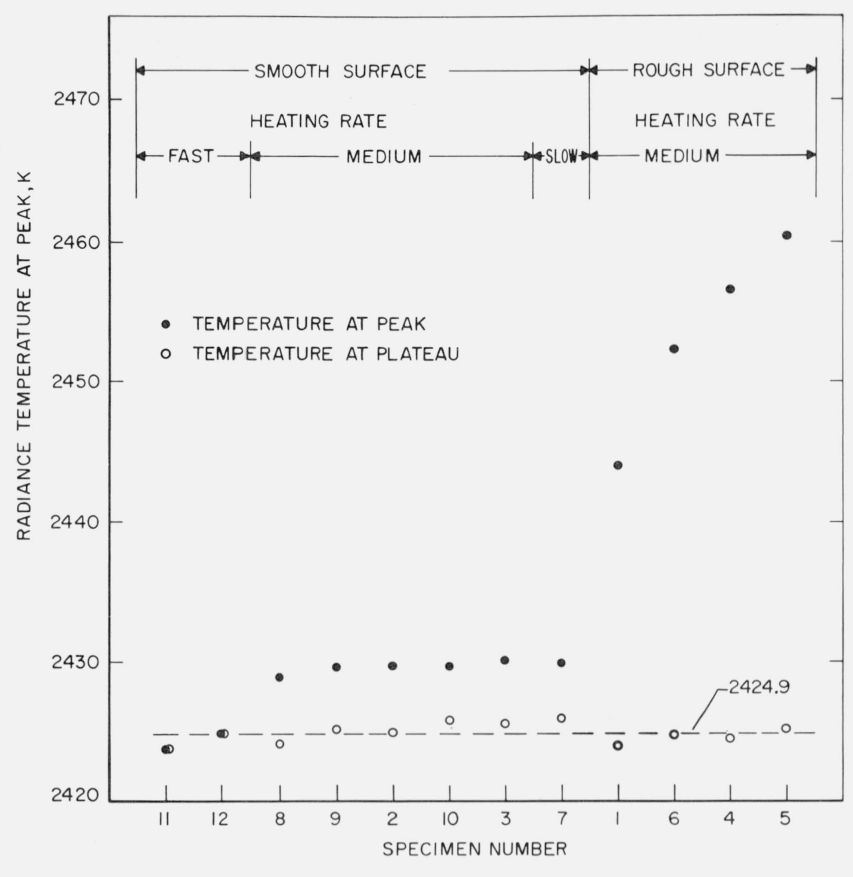

FIGURE 5. Radiance temperature (at $650 \mathrm{~nm}$ ) at the peak and at the plateau for the niobium specimens.

The single value for the plateau of each specimen corresponds to the average over the entire plateau for that specimen. were fitted to a linear function in time using the least squares method. The slopes of the linear functions (table 1) do not show any significant bias with respect to direction. The maximum temperature difference between the beginning and the end of the plateau (corresponding to the slope in the plateau) was in the range from 0.1 to $0.7 \mathrm{~K}$. The standard deviation of an individual temperature from the linear function was the same as the standard deviation obtained by direct averaging of the temperatures.

The measured radiance temperatures at the plateau are shown in figure 6 for two specimens having "smooth" surfaces representing two different heating rates (table 1). The plateaus do not show any anomalies and are horizontal from the beginning to the end. However, the results are somewhat different in the case of specimens having initially rough surfaces (fig. 7). Temperature instabilities are observed during the initial melting period, which subside during the second half yielding a horizontal plateau. The temperatures in the anomalous region are approximately 1 to $3 \mathrm{~K}$ above those at the stable plateau.

The average radiance temperature at the melting point for the twelve specimens was $2424.9 \mathrm{~K}$, with an average absolute difference of $0.6 \mathrm{~K}$ and a maximum difference of $1.2 \mathrm{~K}$. The results are presented in figure 8. It may be concluded that the radiance temperature (at $650 \mathrm{~nm}$ ) of niobium at its melting point is $2425 \mathrm{~K}$.

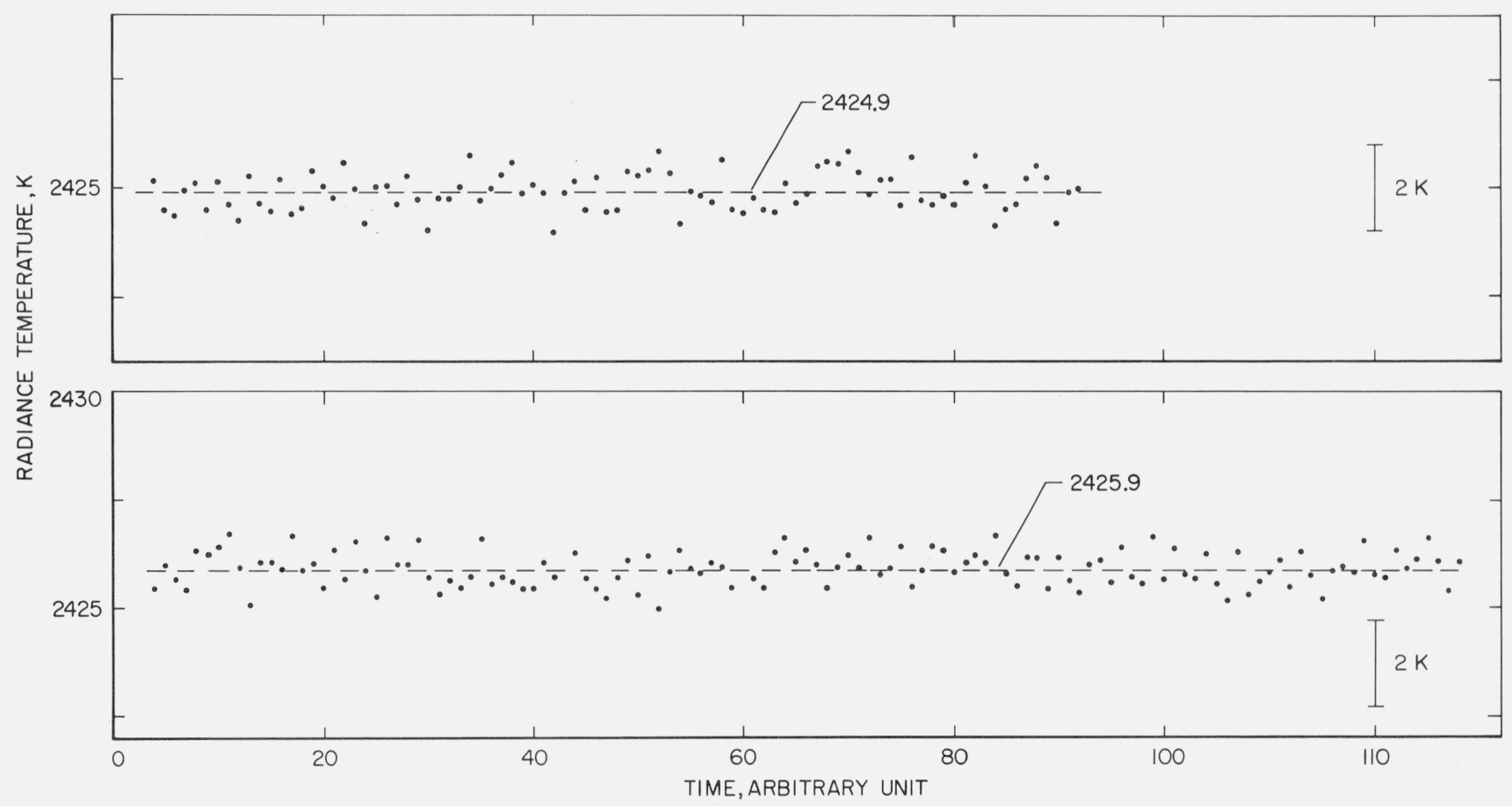

FIGURE 6. Radiance temperature (at $650 \mathrm{~nm}$ ) of niobium (with initially "smooth" surface) at its melting point.

Upper trace is for specimen-2, and lower trace is for specimen-7. One time unit is $0.833 \mathrm{~ms}$. 


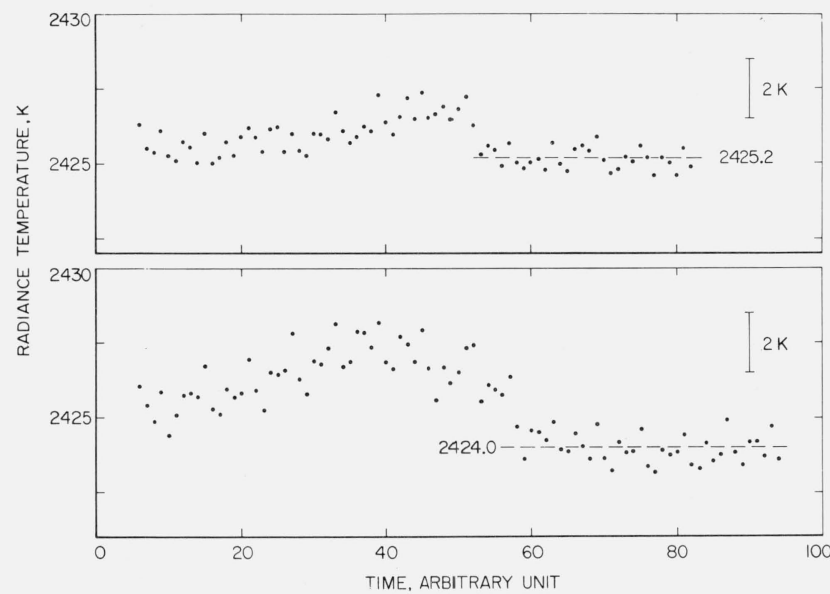

FIGURE 7. Radiance temperature (at $650 \mathrm{~nm}$ ) of niobium (with initially "rough" surface) at its melting point.

Upper trace is for specimen-5, and lower trace is for specimen-1. One time unit is $0.833 \mathrm{~ms}$.

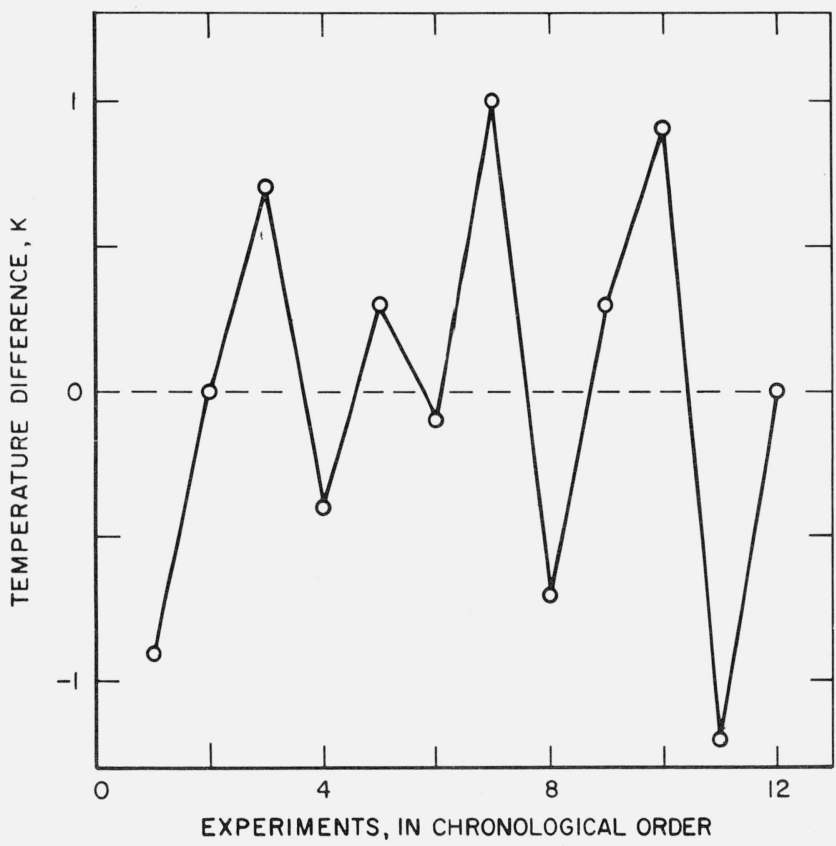

FIGURE 8. Difference of radiance temperature (at the melting point of niobium, at $650 \mathrm{~nm}$ ) for individual experiments from their average value of $2424.9 \mathrm{~K}$ (represented by the "zero" line).

\section{Estimate of Errors}

The details of sources and estimates of errors in high-speed experiments similar to those conducted in this study are given in an earlier publication [3]. Specific items in the error analysis were recomputed whenever the present conditions differed from those in the earlier study. The imprecision ${ }^{2}$ of temperature measurements, during heating as well as melting periods,

${ }^{2}$ Imprecision refers to the standard deviation of an individual temperature as computed from the difference between the measured value and that from the smooth function obtained by the least squares method. is approximately $0.5 \mathrm{~K}$ (table 1 ). Inaccuracy ${ }^{3}$ of temperature measurements near and at the melting point of niobium is estimated to be not more than $7 \mathrm{~K}$. The major single source contributing to this inaccuracy is the uncertainty in the calibration of the tungsten filament standard lamp (approximately $3 \mathrm{~K}$ at $2400 \mathrm{~K}$ ). The melting point depression due to the impurities in the specimens is estimated to be not more than $2 \mathrm{~K}$. It may be concluded that the inaccuracy of the measured radiance temperature of niobium at its melting point is not more than $10 \mathrm{~K}$.

It may be seen from table 1 that the imprecision of temperature measurements during heating of the specimen (before reaching the melting point) was approximately the same as that during the melting period. This indicates that in the experiment the initial melting phase progressed normally and that there were no undesirable effects during melting of the specimen, such as vibration of the specimen, instantaneous development of hot spots in the specimen, and random changes in the specimen surface conditions.

\section{Discussion}

The results of this study show that radiance temperature at the melting point of niobium is reproducible and is independent of: (a) the initial surface conditions of the specimen, (b) the environment (vacuum or argon) in which the specimen is heated, and (c) the heating rate of the specimen.

The 12 experiments performed under different conditions yielded an average value of $2424.9 \mathrm{~K}$ for the radiance temperature, with an average absolute difference of $0.6 \mathrm{~K}$ and a maximum difference of $1.2 \mathrm{~K}$. The preliminary results on two niobium specimens reported in an earlier publication [1] had yielded an average value of $2423.3 \mathrm{~K}$, which is only $1.6 \mathrm{~K}$ below the present value.

Considering $2750 \mathrm{~K}$ for the melting point of niobium [1] and $2425 \mathrm{~K}$ for the radiance temperature at the melting point, a value of 0.340 is obtained for the normal spectral emittance (at $650 \mathrm{~nm}$ ) at the melting point of niobium. Earlier measurement, utilizing the same pulse heating system, on tubular niobium specimens in the range 1700 to $2300 \mathrm{~K}$ showed a linear variation of normal spectral emittance with temperature [6]. Extrapolation of these results to the melting point yields 0.348 for normal spectral emittance, which is approximately 2 percent higher than the present value. Measurement of normal spectral emittance of niobium near its melting point is reported in the literature to be 0.362 [7]; this is approximately 6 percent higher than the present value. In the case of solid surfaces, departure, in varying degrees, from ideal surface conditions may have been partially responsible for the high values.

This may be demonstrated by considering the present results on "rough" specimens. From table 1 (last column) it may be seen that for the "rough" specimens a considerable difference exists between

${ }^{3}$ Inaccuracy refers to the estimated total error (random and systematic). 
the peak and plateau temperatures. This difference in temperature corresponds to a difference in normal spectral emittance ranging from 7 to 14 percent for the four "rough" specimens. In the case of the "smooth" specimens, corresponding average difference in emittance is approximately 2 percent. The above substantiate, both in magnitude and in direction, the difference between present results and those reported in the literature.

The radiance temperature (at $645 \mathrm{~nm}$ ) of liquid niobium at its melting point was measured recently using a levitation calorimeter [8]. The reported result of $2405 \mathrm{~K}$ is $20 \mathrm{~K}$ lower than the present value. No satisfactory explanation has been found for this discrepancy.

It may be noted that, with the present system, it was not possible to follow the entire melting process because the specimen collapsed and opened the main electrical circuit prior to the completion of melting.

In conclusion, the results of this study have shown the constancy and reproducibility of the radiance temperature of niobium at its melting point. Compared to the difficulties encountered in the construction and operation of blackbody cavities at temperatures above $2000 \mathrm{~K}$, the scheme of measuring radiance temperature at the melting point of selected substances may be an easier, more accurate, and in addition more practical approach for performing secondary calibration on instruments and for conducting overall on-the-spot checks on complicated measurement systems at high temperatures. This suggests the extension of investigations, similar to those reported in this paper, to other refractory metals at temperatures above $2500 \mathrm{~K}$.
The author expresses his gratitude to C. W. Beckett for his continued interest and encouragement of research in high-speed measurement methods. The contribution of M. S. Morse in connection with electronic instrumentation is also greatly appreciated.

\section{References}

[1] Cezairliyan, A., Measurement of melting point, normal spectral emittance (at melting point), and electrical resistivity (above $2650 \mathrm{~K}$ ) of niobium by a pulse heating method, High Temperatures-High Pressures, 4, 453 (1972).

[2] Foley, G. M., High-speed optical pyrometer, Rev. Sci. Instr. 41, 827 (1970).

[3] Cezairliyan, A., Morse, M. S., Berman, H. A., and Beckett, C. W., High-speed (subsecond) measurement of heat capacity, electrical resistivity, and thermal radiation properties of molybdenum in the range 1900 to $2800 \mathrm{~K}$, J. Res. Nat. Bur. Stand. (U.S.), 74A (Phys. and Chem.), No. 1, 65-92 (Jan.-Feb. 1970).

[4] Cezairliyan, A., Design and operational characteristics of a highspeed (millisecond) system for the measurement of thermophysical properties at high temperatures. J. Res. Nat. Bur. Stand. (U.S.), 75C (Eng. and Instr.), No. 1, 7 (1971).

[5] International Practical Temperature Scale of 1968, Metrologia, 5, 35 (1969).

[6] Cezairliyan, A., High-speed (subsecond) measurement of heat capacity, electrical resistivity, and thermal radiation properties of niobium in the range 1500 to $2700 \mathrm{~K}$, J. Res. Nat. Bur. Stand. (U.S.), 75A (Phys. and Chem.), No. 6, 565-571 (Nov.Dec. 1971).

[7] Pemsler, J. P., Thermodynamics of interaction of niobium and tantalum with oxygen and nitrogen at temperatures near the melting point, J. Electrochem. Soc. 108, 744 (1961).

[8] Bonnell, D. W., Treverton, J. A., Valerga, A. J., and Margrave, J. L., The emissivities of liquid metals at their fusion temperatures, Proceedings of the Fifth Symposium on Temperature, in press.

(Paper 77A3-771) 